\title{
Bacterial resistance trends among intraoperative bone culture of chronic osteomyelitis in an affiliated hospital of South China for twelve years
}

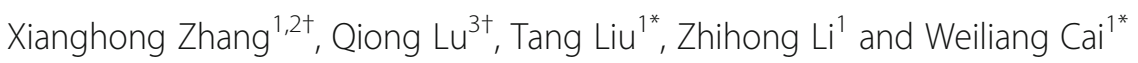

\begin{abstract}
Background: The purpose of this study was to gather temporal trends on bacteria epidemiology and resistance of intraoperative bone culture from chronic ostemyelitis at an affiliated hospital in South China.

Method: Records of patients with chronic osteomyelitis from 2003 to 2014 were retrospectively reviewed. The medical data were extracted using a unified protocol. Antimicrobial susceptibility testing was carried out by means of a unified protocol using the Kirby-Bauer method, results were analyzed according to Clinical and Laboratory Standards Institute definitions.

Result: Four hundred eighteen cases met our inclusion criteria. For pathogen distribution, the top five strains were Staphylococcus aureus (27.9\%); Pseudomonas aeruginosa (12.1\%); Enterobacter cloacae (9.5\%); Acinetobacter baumanii (9.0\%) and Escherichia coli (7.8\%). Bacterial culture positive rate was decreased significantly among different year-groups. Mutiple bacterial infection rate was $28.1 \%$. One strain of Staphylococcus aureus was resistant to linezolid and vancomycin. Resistance of Pseudomonas aeruginosa stains to Cefazolin, Cefuroxime, Cefotaxime, and Cefoxitin were 100\% nearly. Resistance of Acinetobacter baumanii stains against Cefazolin, Cefuroxime were 100\%. Ciprofloxacin resistance among Escherichia coli isolates increased from 25 to 44.4\%. On the contrary, resistance of Enterobacter cloacae stains to Cefotaxime and Ceftazidime were decreased from 83.3 to $36.4 \%$.

Conclusions: From 2003 to 2014, positive rate of intraoperative bone culture of chronic osteomyelitis was decreased; the proportion of Staphylococcus aureus was decreased gradually, and our results indicate the importance of bacterial surveilance studies about chronic osteomyelitis.
\end{abstract}

Keywords: Chronic osteomyelitis, Bacterial culture positive rate, Intra-operative bone culture, Long-term secular trends, antibiotic resistance

\section{Background}

Osteomyelitis, as a serious deep bone infection, is caused by microorganisms [1, 2], and persistence of microorganisms, low-grade inflammation are chronic osteomyelitis characteristics [3, 4]. Trueta J demonstrated that hematogenous osteomyelitis was caused by a single agent, while other mechanisms of infection showed

\footnotetext{
* Correspondence: liutang1204@csu.edu.cn; caiweiliang@csu.edu.cn

${ }^{+}$Xianghong Zhang and Qiong Lu are co-first author.

'Department of Orthopedics, The Second Xiangya Hospital of Central South University, 139\# Middle Renmin Road, Changsha 410011, Hunan, China Full list of author information is available at the end of the article
}

poymicrobial infection [5]. Hematogenous osteomyelitis was considered as predominantly pediatric disease with $85 \%$ of patients aged below 17 years, while about $47-50 \%$ of all osteomyelitis was post-traumatic in adult patients [6]. Staphylococcus species was the most common isolated microorganism in most types of osteomyelitis, approximately affecting $50-70 \%$ of cases $[7,8]$, and the second and third were Enterobacteriaceae and Pseudomonas species [9]. Meanwhile, the treatment of chronic osteomyelitis remains challenge, and multidisciplinary approach including adequate surgery and antibiotics were required $[10,11]$. Though microbiologic testing

(C) The Author(s). 2019 Open Access This article is distributed under the terms of the Creative Commons Attribution 4.0 International License (http://creativecommons.org/licenses/by/4.0/), which permits unrestricted use, distribution, and 
would cause false-negative result, it's an useful mean to identifying the organism [12], and intra-operative bone culture appears to predict the complete etiologic organisms more reliably [13].

Osteomyelitis' commonly isolated microorganisms were related to age and susceptibility factors, which including injectable drug users, immunocompromised, urinary infection, orthopedic fixation devices, diabetes mellitus and so forth [14-16]. With the rapid development of antimicrobial resistance and expression of virulence factors, regardless of patient's immune status, the bacterial distribution, bacterial culture positive rate and antibiotic resistance of osteomyelitis had changed gradually [17]. There was few studies about continuous changes of bacterial culture positive rate, causative organisms and antibiotic resistance for intraoperative bone culture from chronic osteomyelitis in the same hospital over a period of time. Up to now, few study was from mainland China, a developing country. Our present study was aimed to evaluate the changing trends of positive rate, causative organisms and antibiotic resistance for intraoperative bone culture from chronic osteomyelitis over a 12 -year periods in a south-central region of China. Our this study can help to see the status of bacterial culture positive rate of intraoperative bone and antimicrobial resistance of causative organisms of chronic osteomyelitis, even can help to take more effective measures for treatment.

\section{Methods}

We retrospectively reviewed the medical records of patients who were admitted to the orthopedics department with chronic osteomyelitis from January 12,003, to December 31,2014 . The health facility is an university teaching hospital that located in the south central region of China. Medical record information included the basic information of patients, cause of osteomyelitis, the bone(s) affected, the status of bacterial culture, antimicrobial susceptibility testing, results of laboratory tests and radiography, and even pathological examination. Chronic ostemyelitis was defined clinically as bone infection with clinical signs persisting for more than 10 days or the relapse of a previously treated or untreated osteomyelitis [18], and bone infection was defined as at least two bone cultures with the same organism growth, or one positive bone culture combined with the intraoperative finding of purulence, acute inflammation on histologic examination consistent with infection, or a sinus tract communicating to the bone [19]. Patients were choose in accordance with the unified standards [20]. At first, we picked over cases with chronic osteomyelitis which were diagnosed based on above definition through the medical records; and then chronic osteomyelitis who had taken intraoperative bone culture was sorted out; Lastly, we had shut out cases who had not quit antibiotic therapy for at least 1 week within the period preceding admission for surgery. In order to avoid duplicate counts, only one isolate from the same species was included per patients [21]. Specimens from the depths of sinus tracks were taken for surgery. Marrow pus, curetting, sequestra and bone biopsy were obtained at surgery, and sent through appropriate transport medium for microbiological examination and culture. All samples were inoculated onto a pair of blood agar and one Mac Conkey agar plates. One blood agar plate was inoculated anaerobically for $48 \mathrm{~h}$ and the other two plates aerobically for $24 \mathrm{~h}$. Special identification of the isolates was performed by standard biochemical methods, and antimicrobial susceptibility testing was carried out by means of a unified protocol using the Kirby-Bauer method, results were analyzed according to Clinical and Laboratory Standards Institute (CLSI) criteria (as applicable each year) [22].

Statistical analysis was performed with the Statistical package for social sciences (SPSS)21.0 software (SPSS Inc., Chicago, IL, USA). Patient's demographics were described as the mean and the standard deviation or as the count and percentage as appropriate. Chi-square test or Kruskal-Wallis $\mathrm{H}$ test was used to analysis the difference of rates about numeration data. All significance tests were two-sided, and $p$ value of less than 0.05 was considered statistically significant for all tests.

\section{Results}

In order to increase the number of different group, we divided 2 years into one group. The mean age was $39.3 \pm 16.5$ years, and $10.8 \%$ of the patients was younger than 18 years, $50.7 \%$ was $18-45$ years, and $38.5 \%$ of the cohort was 45 years or older; and 327 of patients were males (78.2\%). The majority of the infections (95.7\%) involved only one bone, and the most common anatomical affected sites was tibia (35.9\%); followed by femur (27.5\%); calcaneus $(5.7 \%)$ and humerus $(2.2 \%)$. We have observed an increasing proportion of culture-negative (28.5\%), and positive rates were statistically different between all year-groups $\left(x^{2}=11.95, P=0.036\right)$. Agespecific and Etiology-specific positive rate for intraoperative bone culture were shown in Tables 1 and 2 . The year-trend of positive rate was not significantly different in the age-group of younger than 18 years $(p=0.062)$ and group of 45 years or older $(p=0.117)$, but were statistically different in the group of $18-45$ years $(p=0.003)$. In the risk-factors of different etiology, positive rate was statistically different in traumatic-group $(p=0.00)$ and hematogenic-group $(p=0.01)$.

The total number of bacterial isolated from 418 cases was 398. The percentage of the top five species was shown in Fig. 1: Staphylococcus aureus infections was responsible for $27.9 \%$, followed by Pseudomonas 
Table 1 Age-specific positive rate for intraoperative bone culture of chronic osteomyelites (2003-2014)

\begin{tabular}{clll}
\hline & \multicolumn{2}{l}{ Positive-rate(\%) } & \\
\cline { 2 - 4 } Age group (yr) & $<18$ & $18-44$ & $\geq 45$ \\
\hline Year group (yr) & 25.0 & 46.4 & 41.2 \\
$2003-2004$ & 55.6 & 49.1 & 61.9 \\
$2005-2006$ & 60.0 & 68.1 & 66.7 \\
$2007-2008$ & 75.0 & 70.0 & 62.5 \\
$2009-2010$ & 80.0 & 80.0 & 78.2 \\
$2011-2012$ & 66.7 & 70.1 & 67.8 \\
$2013-2014$ & 10.530 & 18.270 & 8.811 \\
$H$ value & 0.062 & $0.006^{*}$ & 0.117 \\
$P$ value & ${ }^{*} P<0.05$ statistically significant & &
\end{tabular}

aeruginosa (12.1\%); Enterobacter cloacae (9.5\%); Acinetobacter baumanii (9.0\%) and Escherichia coli (7.8\%). Mutiple bacterial infection rate was $28.1 \%$, which included three strains infection rate (5.02\%) and double bacterial infection rate (23.08\%). For Staphylococcus aureus, We found one strain in group of 2009-2010, which was resistant to linezolid; and found one strain in group of 2011-2012 resistant to vancomycin and linezolid. Ciprofloxacin and Erythromycin resistance levels decreased from 41.7 to $30 \%$ and from 66.7 to $46.7 \%$ (Table 3). For Pseudomonas aeruginosa, Cefazolin, Cefuroxime, Cefotaxime, and Cefoxitin resistance levels were $100 \%$ nearly (Table 4). For Enterobacter cloacae, We found nearly all resistant to Cefazolin, Cefuroxime, Cefoperazone and Cefoxitin; Cefotaxime and Ceftazidime resistance levels decreased from 100 to $54.5 \%$ and from 83.3 to $36.4 \%$, respectively (Table 5). For Acinetobacter baumanii, they were stable $100 \%$ nearly to Cefazolin and Cefuroxime (Table 6). For Escherichia coli, Gentamicin resistance levels decreased from 50 to

Table 2 Etiology-specific positive rate for intraoperative bone culture of chronic osteomyelites (2003-2014)

\begin{tabular}{cllll}
\hline Pathogenesis & \multicolumn{4}{l}{ Positive-rate(\%) } \\
\cline { 2 - 5 } & traumatic & adjacent infection & hematogenic & others \\
\hline Year group & & & 27.31 & 35.7 \\
$2003-2004$ & 53.8 & 16.7 & 57.1 & 66.7 \\
$2005-2006$ & 50.9 & 37.5 & 100.0 & 63.6 \\
$2007-2008$ & 68.4 & 55.6 & 80.0 & 61.3 \\
$2009-2010$ & 69.1 & 66.7 & 90.0 & 64.3 \\
$2011-2012$ & 88.7 & 70.6 & 100.0 & 59.0 \\
$2013-2014$ & 79.7 & 50.0 & 16.686 & 4.191 \\
H value & 28.081 & 6.900 & $0.005^{*}$ & 0.522 \\
$P$ value & $0.000^{*}$ & 0.228 & & \\
\hline *P $P$ 0.05 statisticaly significant &
\end{tabular}

${ }^{*} P<0.05$ statistically significant
$22.2 \%$, respectively. However, a marked increase of resistance was seen for Ciprofloxacin from 25 to 44.4\%, respectively (Table 7).

\section{Discussion}

A culture directed antibiotic therapy is proper treatment of chronic osteomyelitis [23]. The culture of material should obtained by superficial swabbing of the wound, depths of sinus track, intraoperative and even specimens by other methods. Culture of superficial material swabbing of the would was considered adequate to identify pathogens causing osteomyelitis before 1978 [24], but recent literature have suggested that bone specimen cultures were more reliable compared to sinus track culture on the complete etiologic organisms [20]. Therefore, we taken patients who had made intraoperative bone cultures into our these studies for the aim of gathering temporal trends. Although all kinds of organisms, including bacteria, viruses, parasites, fungi, and tuberculosis may cause osteomyelitis, bone infection was mainly caused by pyogenic bacteria and mycobacteria. Tong SY had drawn a conclusion that Staphylococcus aureus was responsible for 80 to $90 \%$ of the cases of pyogenic osteomylitis, while Staphylococcus epidermidis was the most abundant skin flora [25]. We have discovered Staphylococcus aureus infection was responsible for $27.9 \%$ of the total number of cases, followed by Pseudomonas aeruginosa (12.1\%) and Enterobacter cloacae (9.5\%). Though Staphylococcus aureus was still the most common pathogenic bacteria, the proportion was decreased year by year due to long-time, unreasonable and even abuse using agents and increase of high-energy open fractures [26, 27].

Because chronic osteomyelitis require antibiotics therapy for months to years, therefore, chronic osteomyelitis entails a major financial burden and substantially affects the quality of life. This situation made the accurate identification of pathogen as an absolute cornerstone of antimicrobial therapy. We suggested that the treatment of chronic osteomyelitis according to the microbiological analysis from surgery or bone biopsy. Consistent with temporal trends in the distribution of chronic osteomylitis, we observed a decline in the proportion of patients with gram-positive bacteria infections and an increase in the proportion of cases with culture-negative over time. Some recent studies had described an increase in culture-negative cases because of early antibiotic administration and even rampant use of antibiotics [28]. Failure to incubate anaerobic cultures for sufficient time might also have contributed to the culture-negative rate [29]. Culture-negative specimens may because of tuberculosis and fungal infection which should require further investigation using specialized techniques. Biofilms [30] and failure to recognize small colony variants (SCVs) may cause false-negative culture results [31]. Such 


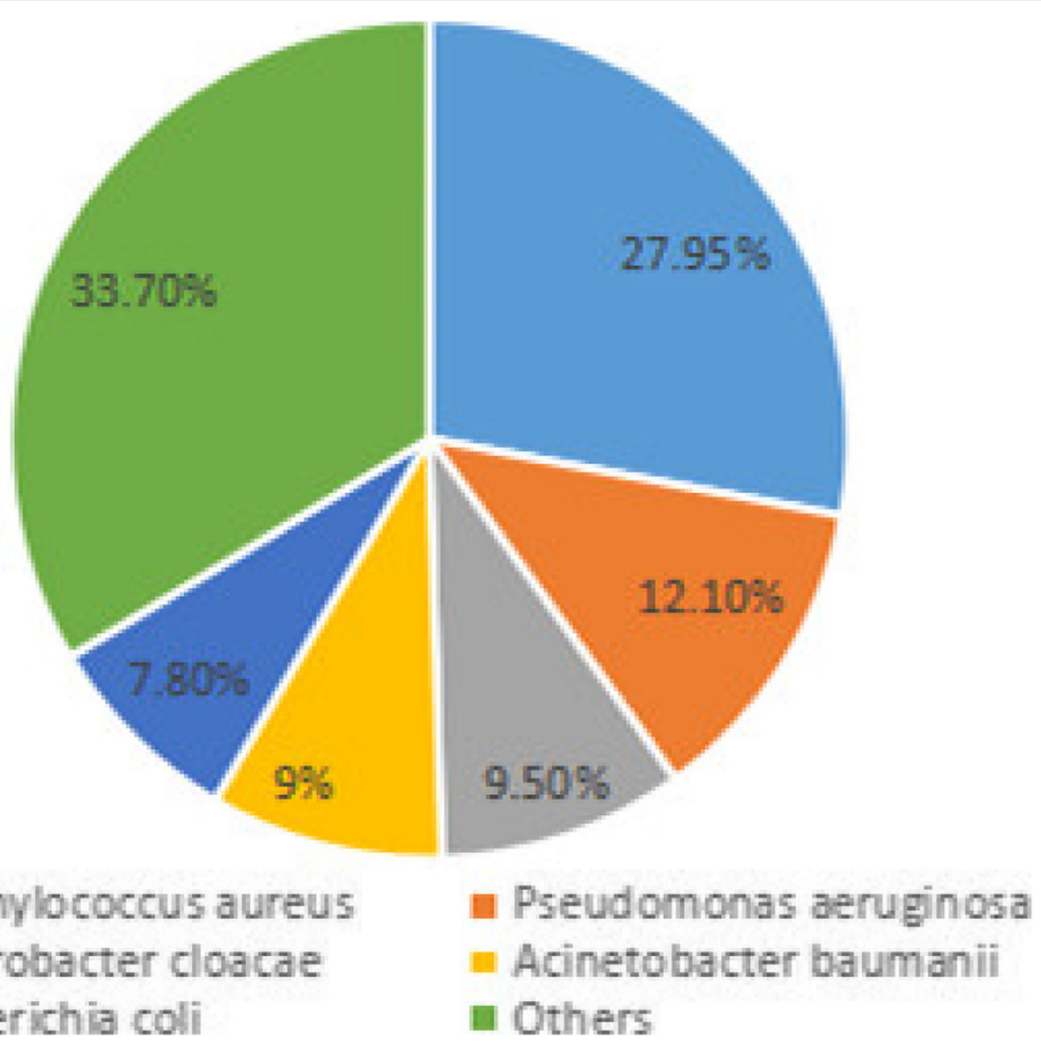

Fig. 1 The pathogen distribution of chronic osteomyelitis from 2003 to 2014

bacteria are in a stationary phase of growth because oxygen and glucose are limited in biofilms [32]. Small colony variants $(\mathrm{SCVs})$ were first depicted exceed 100 years, and it was 20 years ago to described the relationship between chronic staphylococcal infection and the presence of SCVs [33]. SCVs figure a very heterogeneous bacterial population found in different staphylococcal species. In fact, SCVs are difficult to recover, to identify and to store. Clinical studies had found that SCVs exhibit so-called phenotypic (or functional) resistance beyond the classical resistance mechanisms by their intracellular lifestyle, and SCVs can often be retrieved from therapy-refractory courses when it was infected [33]. Therefore, we recommended that tissue for culture of aerobic organism, anaerobic organism, tubeculosis and fungal must be obtained during intraoperative in

Table 3 Resistance rates(\%) of Staphylococcus aureus to antimicrobial agents

\begin{tabular}{|c|c|c|c|c|c|c|}
\hline Antimicrobial agent & $\begin{array}{l}2003-2004 \\
(n=5)\end{array}$ & $\begin{array}{l}2005-2006 \\
(n=13)\end{array}$ & $\begin{array}{l}2007-2008 \\
(n=11)\end{array}$ & $\begin{array}{l}2009-2010 \\
(n=17)\end{array}$ & $\begin{array}{l}2011-2012 \\
(n=35)\end{array}$ & $\begin{array}{l}2013-2014 \\
(n=30)\end{array}$ \\
\hline Vancomycin & 0 & 0 & 0 & 0 & 2.9 & 0 \\
\hline Linezolid & 0 & 0 & 0 & 6.3 & 2.9 & 0 \\
\hline Teicoplanin & - & 0 & 0 & 0 & 0 & 0 \\
\hline Rifampin & 40.0 & 12.5 & 0 & 10.0 & 25.0 & 20.0 \\
\hline Levofloxacin & - & - & 0 & 43.8 & 54.3 & 33.3 \\
\hline Ciprofloxacin & 0 & 41.7 & 10.0 & 26.7 & 25.7 & 30.0 \\
\hline Gentamicin & 20.0 & 46.2 & 0 & 26.7 & 34.3 & 31.0 \\
\hline Clindamycin & - & 36.4 & 10.0 & 30.8 & 62.9 & 44.8 \\
\hline Erythromycin & 40.0 & 66.7 & 14.3 & 36.4 & 65.7 & 46.7 \\
\hline Penicillin G & 33.3 & 100.0 & 81.8 & 87.5 & 94.3 & 88.0 \\
\hline Ampicillin & - & 100.0 & 90.0 & 92.3 & 96.0 & 95.8 \\
\hline
\end{tabular}


Table 4 Resistance rates(\%) of Pseudomonas aeruginosa to antimicrobial agents

\begin{tabular}{|c|c|c|c|c|c|c|}
\hline Antimicrobial agent & $\begin{array}{l}2003-2004 \\
(n=1)\end{array}$ & $\begin{array}{l}2005-2006 \\
(n=8)\end{array}$ & $\begin{array}{l}2007-2008 \\
(n=3)\end{array}$ & $\begin{array}{l}2009-2010 \\
(n=7)\end{array}$ & $\begin{array}{l}2011-2012 \\
(n=14)\end{array}$ & $\begin{array}{l}2013-2014 \\
(n=15)\end{array}$ \\
\hline Amikacin & 0 & 25.0 & 0 & 14.3 & 14.3 & 0 \\
\hline Gentamicin & 0 & 25.0 & 33.3 & 42.9 & 28.6 & 13.3 \\
\hline Piperacillin & 0 & 37.5 & 66.7 & 28.6 & 15.4 & 14.3 \\
\hline Piperacillin/taazobactam & - & 20.0 & 66.7 & 28.6 & 21.4 & 0 \\
\hline Cefazolin & 100.0 & 100.0 & 100.0 & 100.0 & 100.0 & 100.0 \\
\hline Cefuroxime & 100.0 & 100.0 & - & 100.0 & 100.0 & 100.0 \\
\hline Cefotaxime & - & 100.0 & 0 & 75.0 & 100.0 & 100.0 \\
\hline Ceftazidime & 0 & 12.5 & 66.7 & 14.3 & 14.3 & 6.7 \\
\hline Cefepime & - & 0 & 0 & 28.6 & 14.3 & 0 \\
\hline Cefoxitin & 100.0 & 100.0 & 100.0 & - & - & 100.0 \\
\hline Imipenem & 0 & 0 & 33.3 & 14.3 & 7.7 & 6.7 \\
\hline Meropenem & - & 0 & 50.0 & 66.7 & 27.3 & 0 \\
\hline Ciprofloxacin & 0 & 37.5 & 0 & 14.3 & 21.4 & 13.3 \\
\hline
\end{tabular}

order to identify all the etiologic organisms. Treatment failures in chronic osteomyelitis will then be reduced to the minimum.

The published literature had shown the tibia was the most commonly affected site [28], and ours finding have corroborated that tibia (36.1\%) was the common site. Osteomyelitis encompasses a broad spectrum of disease mechanisms, and the three generally accepted categories was hematogenic, contiguous to an adjacent infection focus, and direct bacterial inoculation from a traumatic. Our study discovered that direct bacterial inoculation from traumatic was responsible for $54.3 \%$ of all cases, followed by adjacent infection (8.6\%); hematogenic (8.1\%) and others of unexplained factor (28.9\%). Along with the advances were made in the management of chronic osteomyelitis, the epidemiology of the condition appears to evolve over time. Chen AT has made a conclusion that the incidence of bone infection may continue to rise because of multiple factors including improved diagnosis, increasing patient risk factors, and increased needs for arthroplasties [34]. Mader JT concluded that the increased survival following traumatic injury has been accompanied by an increased occurrence of post-traumatic osteomyelitis [35]. The patients with post-traumatic osteomyelitis require repeated surgery and long-time agents using, therefore, it may lead to bacterial resistant and lower bacterial culture positive rate.

In our study, we described the trends in the change of positive rate for intraoperative bone culture over time and demonstrated that the positive rate changed substantially over 12-year from 2003 to 2014 . We discovered the

Table 5 Resistance rates(\%) of Enterobacter cloacae to antimicrobial agents

\begin{tabular}{|c|c|c|c|c|c|c|}
\hline Antimicrobial agent & $\begin{array}{l}2003-2004 \\
(n=4)\end{array}$ & $\begin{array}{l}2005-2006 \\
(n=2)\end{array}$ & $\begin{array}{l}2007-2008 \\
(n=12)\end{array}$ & $\begin{array}{l}2009-2010 \\
(n=6)\end{array}$ & $\begin{array}{l}2011-2012 \\
(n=3)\end{array}$ & $\begin{array}{l}2013-2014 \\
(n=11)\end{array}$ \\
\hline Amikacin & 50.0 & 0 & 45.5 & 33.3 & 0 & 9.1 \\
\hline Gentamicin & 50.0 & 100.0 & 66.7 & 66.7 & 66.7 & 45.5 \\
\hline Piperacillin & 50.0 & 100.0 & 100.0 & 83.3 & 100.0 & 63.6 \\
\hline Cefazolin & 100.0 & 100.0 & 100.0 & 100.0 & 100.0 & 100.0 \\
\hline Cefuroxime & 75.0 & 100.0 & 90.9 & 66.7 & 100.0 & 100.0 \\
\hline Cefotaxime & - & 100.0 & 90.9 & 83.3 & 100.0 & 54.5 \\
\hline Ceftazidime & 50.0 & 0 & 83.3 & 83.3 & 33.3 & 36.4 \\
\hline Cefepime & 100.0 & 50.0 & 66.7 & 66.7 & 100.0 & 45.5 \\
\hline Cefoperazone & 100.0 & 100.0 & 100.0 & - & - & 100.0 \\
\hline Cefoxitin & 100.0 & 50.0 & 100.0 & - & - & 100.0 \\
\hline Imipenem & 0 & 0 & 0 & 0 & 0 & 9.1 \\
\hline Meropenem & 0 & 0 & 33.3 & - & - & 18.2 \\
\hline Ciprofloxacin & 0 & 100.0 & 54.5 & 66.7 & 100.0 & 9.1 \\
\hline
\end{tabular}


Table 6 Resistance rates(\%) of Acinetobacter baumanii to antimicrobial agents

\begin{tabular}{|c|c|c|c|c|c|c|}
\hline Antimicrobial agent & $\begin{array}{l}2003-2004 \\
(n=0)\end{array}$ & $\begin{array}{l}2005-2006 \\
(n=3)\end{array}$ & $\begin{array}{l}2007-2008 \\
(n=6)\end{array}$ & $\begin{array}{l}2009-2010 \\
(n=8)\end{array}$ & $\begin{array}{l}2011-2012 \\
(n=17)\end{array}$ & $\begin{array}{l}2013-2014 \\
(n=2)\end{array}$ \\
\hline Amikacin & - & 66.7 & 66.7 & 50.0 & 64.7 & 100.0 \\
\hline Gentamicin & - & 100.0 & 100.0 & 75.0 & 82.4 & 100.0 \\
\hline Piperacillin & - & 100.0 & 66.7 & 75.0 & 88.2 & 100.0 \\
\hline Piperacillin/taazobactam & - & 100.0 & 100.0 & 75.0 & 88.2 & 100.0 \\
\hline Cefazolin & - & 100.0 & 100.0 & 100.0 & 100.0 & 100.0 \\
\hline Cefuroxime & - & 100.0 & 100.0 & 100.0 & 100.0 & - \\
\hline Cefotaxime & - & 100.0 & 80.0 & 75.0 & 82.4 & 100.0 \\
\hline Ceftazidime & - & 100.0 & 60.0 & 50.0 & 76.5 & 50.0 \\
\hline Cefepime & - & 100.0 & 100.0 & 50.0 & 70.6 & 50.0 \\
\hline Imipenem & - & 33.3 & 16.7 & 50.0 & 64.7 & 100.0 \\
\hline Meropenem & - & 100.0 & 0 & 80.0 & 75.0 & 100.0 \\
\hline Ciprofloxacin & - & 100.0 & 83.3 & 62.5 & 70.6 & 100.0 \\
\hline
\end{tabular}

bacterial culture positive rate for introperative bone was changed by age-factor over time. Age is an important factor which could determine the etiology of chronic osteomyelitis. In children group, the most common etiology was hematogenous infections. Due to elder cases had experienced a higher frequency of disorder that may lead to infection, such as diabetes mellitus, orthopaedic surgeries and vascular or neurologic insufficiency disease, elder patients were susceptible to chronic osteomyelitis. Host condition has been emphasized because it was the importance factor for chronic osteomyelitis treatment modality. Parkkinen M considered host condition-related risk factors for bone infection included diabetes, arteriosclerosis, alcoholism, obesity, smoking, and aging [36]. Therefore, we should make effort on effective prevention and treatment of older's chronic osteomyelitis since older people are susceptible to be infected and prognosis is poor once chronic osteomyelitis developed.

We made a conclusion that multiple bacterial infection rate was $28.1 \%$, which included three strains infection rate $(5.02 \%)$ and double bacterial infection rate (23.08\%).
We found one stain of Staphylococcus aureus was resistant to linezolid and vancomycin; and we also found stains of Pseudomonas aeruginosa, Enterobacter cloacae and Acinetobacter baumanii were resistant to carbapenems. Carbapenems are the most potent and reliable $\beta$ lactam antibiotics for the treatment of serious infection caused by multidrug-resistant Gram-negative bacterial [37]. Infection of multidrug-resistant bacterial present a serious clinical challenge for physicians in healthcare setting. Treatment options for these infections are limited, and the use of inappropriate empirical antibiotic therapy of delayed appropriate antibiotic therapy can lead to worse outcomes. We also found large fluctuations over time in our study, and taking antibiotic resistance surveillance studies over longer time periods is important.

We realized that our retrospectively investigation may have been influenced by a number of methodological shortcomings. In this regard, retrospective error is inevitable. We believe that it is important to keep in mind that our study focused on chronic osteomyelitis with

Table 7 Resistance rates(\%) of Escherichia coli to antimicrobial agents

\begin{tabular}{|c|c|c|c|c|c|c|}
\hline Antimicrobial agent & $\begin{array}{l}2003-2004 \\
(n=0)\end{array}$ & $\begin{array}{l}2005-2006 \\
(n=4)\end{array}$ & $\begin{array}{l}2007-2008 \\
(n=3)\end{array}$ & $\begin{array}{l}2009-2010 \\
(n=7)\end{array}$ & $\begin{array}{l}2011-2012 \\
(n=8)\end{array}$ & $\begin{array}{l}2013-2014 \\
(n=9)\end{array}$ \\
\hline Amikacin & - & 25.0 & 0 & 14.3 & 25.0 & 0 \\
\hline Gentamicin & - & 50.0 & 100.0 & 57.1 & 50.0 & 22.2 \\
\hline Piperacillin & - & 100.0 & 100.0 & 100.0 & 87.5 & 88.9 \\
\hline Cefazolin & - & 50.0 & 100.0 & 100.0 & 75.0 & 88.9 \\
\hline Cefuroxime & - & 75.0 & 100.0 & 100.0 & 75.0 & 100.0 \\
\hline cefotaxime & - & 25.0 & 100.0 & 100.0 & 75.0 & 77.8 \\
\hline Ceftazidime & - & 0 & 100.0 & 100.0 & 75.0 & 33.3 \\
\hline Cefepime & - & 0 & 100.0 & 100.0 & 75.0 & 66.7 \\
\hline Ciprofloxacin & - & 25.0 & 66.7 & 100.0 & 50.0 & 44.4 \\
\hline
\end{tabular}


intraoperative bone culture and quit antibiotic therapy for at least 1 week. For this reason, the positive rate of intraoperative bone culture may have been higher in these patients in our study in comparison with the patients described in other investigation. Furthermore, the number of cases was distributed uneven each year, although we do not feel that this particular limitation greatly affected the trend of the change of positive rate. Finally, we only made study in a single center in China. Future cohort studies in multi-center study should be taken into research.

\section{Conclusions}

Based on the results of this investigation, the proportion of Staphylococcus aureus is decreased gradually, and our results indicate the importance of bacterial surveilance studies about chronic osteomyelitis. Further research is warranted to replicate these findings in more center and to gather temporal trends on bacterial epidemiology and resistance of chronic osteomyelitis.

\section{Abbreviations}

CLSI: Clinical and Laboratory Standards Institute; SCVs: Small colony variants SPSS: Statistical package for social sciences

\section{Acknowledgements}

We would like to thanks the Second Xiangya Hospital for official permission of this study and microbiology staffs for helping during data collection,

\section{Authors' contributions}

$\mathrm{XHZ}, \mathrm{QL}, \mathrm{TL}, \mathrm{ZHL}$ and WLC conceived the idea, develop the proposal, collected the data, perform the analysis and prepared the manuscript. $\mathrm{XHZ}$ and WLC have made final edition of the document. All authors have read and approved the manuscript.

\section{Funding}

No funding was received to perform this study.

\section{Availability of data and materials}

The datasets used and/or analysed during the current study are available from the corresponding author on reasonable request.

\section{Ethics approval and consent to participate}

This study was ethically approved by the Second Xiangya Hospital committee for clinical research. Permission for data collection was obtained from the hospital laboratory manager. Patients' data obtained in the course of the study were reserved confidential and used only for this study.

\section{Consent for publication}

Not applicable.

\section{Competing interests}

The authors declare that they have no competing interests.

\section{Author details}

${ }^{1}$ Department of Orthopedics, The Second Xiangya Hospital of Central South University, 139\# Middle Renmin Road, Changsha 410011, Hunan, China. ${ }^{2}$ Department of Orthopedics, Liuzhou General Hospital, Guangxi University of Science and Technology, Liuzhou 545000, Guangxi, China. ${ }^{3}$ Department of Pharmacy, The Second Xiangya Hospital of Central South University, Changsha 410011, Hunan, China.
Received: 4 December 2017 Accepted: 10 September 2019

Published online: 18 September 2019

\section{References}

1. Lew DP, Waldvogel FA. Osteomyelitis. Lancet. 2004;364(9431):369-79.

2. Zhang X, Liu T, Li Z, Peng W. Reconstruction with callus distraction for nonunion with bone loss and leg shortening caused by suppurative osteomyelitis of the femur. J Bone Joint Surg Br. 2007:89(11):1509-14.

3. Gentry LO. Management of osteomyelitis. Int J Antimicrob Agents. 1997; 9(1):37-42.

4. Liu T, Zhang X, Li Z, Peng D. Management of combine bone defect and limb-length discrepancy after tibial chronic osteomyelitis. Orthopedics. 2011; 34(8):363-7.

5. Howard JA, Isaacs D. Systematic review of duration and choice of systemic antibiotic therapy for acute haematogenous bacterial osteomyelitis in children. J Paediatr Child Health. 2013;49(9):760-8.

6. Cierny G, Mader JT. Adult chronic osteomyelitis. Orthopedics. 1984;7(10): 1557-64.

7. Mruk AL, Record KE. Antimicrobial options in the treatment of adult staphylococcal bone and joint infections in an era of drug shortages. Orthopedics. 2012;35(5):401-7.

8. Sheehy SH, Atkins BA, Bejon P, Byren I, Wyllie D, Athanasou NA, Berendt AR, McNally MA. The microbiology of chronic osteomyelitis: prevalence of resistance to common empirical anti-microbial regimens. J Inf Secur. 2010; 60(5):338-43.

9. Gogia JS, Meehan JP, Di Cesare PE, Jamali AA. Local antibiotic therapy in osteomyelitis. Semin Plast Surg. 2009;23(2):100-7.

10. Zimmerli W, Sendi P. Orthopaedic biofilm infections. APMIS. 2017;125(4): 353-64

11. Liu C, Zhang $X$, Zhang $X$, Li Z, Xu Y, Liu T. Bone transport with a unilateral external fixator for femoral infected nonunion after intramedullary nailing fixation: a case control study. Medicine (Baltimore). 2019;98(20):e15612.

12. Schmitt SK. Osteomyelitis. Infect Dis Clin N Am. 2017;31(2):325-38.

13. Khatri G, Wagner DK, Sohnie PG. Effect of bone biopsy in guiding antimicrobial therapy for osteomyelitis complicating open wounds. Am J Med Sci. 2001;321(6):367-71.

14. Birt MC, Anderson DW, Bruce Toby E, Wang J. Osteomyelitis: recent advances in pathophysiology and therapeutic strategies. J Orthop. 2016; 14(1):45-52.

15. Brook I. Microbiology and management of joint and bone infections due to anaerobic bacteria. J Orthop Sci. 2008;13(2):160-9.

16. Zemmerli W. Clinical practice. Vertebral osteomyelitis. N Engl J Med. 2010; 362(11):1022-9.

17. Chihara S, Segreti J. Osteomyelitis. Dis Mon. 2010;56(1):5-31.

18. Lew DP, Waldvogel FA. Osteomyelitis. N Engl J Med. 1997;336(14):999-1007.

19. Barbari EF, Hanssen AD, Duffy MC, Stecklberg JM, Ilstrup DM, Harmsen WS, Osmon DR. Risk factors for prosthetic joint infection:case-control study. Clin Infect Dis. 1998;27(5):1247-54.

20. Akinyoola AL, Adegbehingbe $\mathrm{OO}$, Aboderin $\mathrm{AO}$. Therapeutic decision in chronic osteomyelitis: sinus track culture versus intraoperative bone culture. Arch Orthop Trauma Surg. 2009;129(4):449-53.

21. Hu FP, Guo Y, Zhu DM, Wang F, Jiang XF, Xu YC. Resistance trends among clinical isolates in China reported from CHINET surveillance of bacterial resistance, 2005-2014. Clin Microbiol Infect. 2016;22(suppl 1):S9-14.

22. Iyer RN, Jangam RR, Jacinth A, Venkatalakshmi A, Nahdi FB. Prevalence and trends in the antimicrobial susceptibility pattern of salmonella enterica serovars Typhi and Paratyphi A among children in a pediatric tertiary care hospital in South India over a period of ten years: a retrospective study. Eur J Clin Microbiol Infect Dis. 2017;36(12):3399-2404.

23. Yu F, Liu H, Li KH, Lei GH, Gao SG, Chen Y, Liu T. Causative organisms and their antibiotic resistance patterns for childhood septic arthritis in China between 1989 and 2008. Orthopedics. 2011;34(3):179.

24. Ulug M, Ayaz C, Celen MK, Geyik MF, Hosoglu S, Necmioglu S. Are sinustrack cultures reliable for identifying the causative agent in chronic osteomyelitis? Arch Orthop Trauma Surg. 2009;129(11):1565-70.

25. Tong SY, Davis JS, Eichenberger E, Holland TL, Fowler VG Jr. Staphylococcus aureus infections: epidemiology, pathophysiology, clinical manifestations, and management. Clin Microbiol Rev. 2015;28(3):603-61.

26. Del Pozo JL, Patel R. Clinical practice. Infection associated with prosthetic joints. N Engl J Med. 2009;361(8):787-94. 
27. Johnson EN, Burns TC, Hayda RA, Hospenthal DR, Murray CK. Infectious complications of open type III tibial fractures among combat casualties. Clin Infect Dis. 2007:45(4):409-15.

28. Kehrer M, Pedersen C, Jensen TG, Lassen AT. Increasing incidence of pyogenic spondylodiscitis: a 14-year population-based study. J Inf Secur. 2014;68(4):313-20.

29. Butler-Wu SM, Burns EM, Pottinger PS, Magaret AS, Rakeman JL, Matsen FA 3rd, Cookson BT. Optimization of periprosthetic culture for diagnosis of Propionibacterium acnes prosthetic joint infection. J Clin Microbiol. 2011; 49(7):2490-5.

30. Lan L, Bai L, Wang L, He L, Li G, Du W, Shen T, Xiang Z, Wu J, Liu Z, Hu M. Antifungal activity of spider venom-derived peptide lycosin-l against Candida tropicalis. Microbiol Res. 2018;216:120-8.

31. Zimmerli W. Clinical presentation and treatment of orthopaedic implantassociated infection. J Intern Med. 2014:276(2):111-9.

32. Anderl JN, Zahller J, Roe F, Stewart PS. Role of nutrient limitation and stationary-phase existence in Klebsiella pneumoniae biofilm resistance to ampicillin and ciprofloxacin. Antimicrob Agents Chemother. 2003; 47(4):1251-6.

33. Kahl BC, Becler K, Loffler B. Clinical significance and pathogenesis of staphylococcal small colony variants in persistent infection. Clin Microbiol Rev. 2016:29(2):401-27.

34. Chen AT, Vallier HA. Noncontiguous and open fractures of the lower extremity: epidemiology, complications, and unplanned procedures. Injury. 2016;47(3):742-7.

35. Mader JT, Cripps MW, Calhoun JH. Adult posttraumatic osteomyelitis of the tibia. Clin Orthop Relet Res. 1999:360:14-21.

36. Parkkinen M, Madanat R, Lindahi J, Makinen TJ. Risk factors for deep infection following plate fixation of proximal tibia fractures. J Bone Joint Surg Am. 2016;98(15):1292-7.

37. Gupta N, Limbago BM, Patel JB, Kallen AJ. Carbapenem-resistant Enterobacteriaceae:epidemiology and prevention. Clin Infect Dis. 2011; 53(1):60-7.

\section{Publisher's Note}

Springer Nature remains neutral with regard to jurisdictional claims in published maps and institutional affiliations.

Ready to submit your research? Choose BMC and benefit from:

- fast, convenient online submission

- thorough peer review by experienced researchers in your field

- rapid publication on acceptance

- support for research data, including large and complex data types

- gold Open Access which fosters wider collaboration and increased citations

- maximum visibility for your research: over $100 \mathrm{M}$ website views per year

At $\mathrm{BMC}$, research is always in progress.

Learn more biomedcentral.com/submissions 